\title{
Particle size, volume fraction and matrix strength effects on fatigue behavior and particle fracture in 2124 aluminum- $\mathrm{SiC}_{\mathrm{p}}$ composites
}

\author{
Jody N. Hall
}

The University of Michigan, Department of Materials Science and Engineering, Ann Arbor, MI 48109-2136 (USA) and General Motors NAO Manufacturing Center, Warren, MI 48090-9040 (USA)

J. Wayne Jones

The University of Michigan, Department of Materials Science and Engineering, Ann Arbor, MI 48109-2136 (USA)

Anil K. Sachdev

Gereral Motors Research and Development, Warren, MI 48090-9055 (USA)

(Received July 20, 1993)

\begin{abstract}
The effects of particle size, volume fraction and matrix strength on the stress-controlled axial fatigue behavior and the probability of particle fracture were evaluated for 2124 aluminum alloy reinforced with SiC particles. Average particle sizes of 2,5, 9 and $20 \mu \mathrm{m}$ and volume fractions of $0.10,0.20$ and 0.35 were examined for four different microstructural conditions. Tensile and yield strengths and fatigue life were substantially higher in the reinforced alloys. Strength and fatigue life increased as reinforcement particle size decreased and volume fraction loading increased. The frequency of particle fracture during crack propagation was found to be dependent on matrix strength, particle size and volume fraction and on maximum crack tip stress intensity. Particle fracture can be rationalized, phenomenologically, by the application of modified process zone models, originally derived for static fracture processes, and weakest link statistics which account for the dependence of matrix yield strength and flow behavior and particle strength on the probability of particle fracture during monotonic fracture and fatigue crack propagation.
\end{abstract}

\section{Introduction}

The fatigue and fracture behavior of particlereinforced aluminium metal matrix composites has been studied in substantial detail in the past decade and has recently been reviewed by Allison and Jones [1]. It has been demonstrated that in $\mathrm{Al}-\mathrm{SiC}_{\mathrm{p}}$ composites threshold levels and fatigue crack growth rates may be significantly influenced by the presence of reinforcement particles [2-4]. This arises, in part, from the influence of reinforcement particles on crack tip processes such as crack closure, crack defection, crack trapping and, to some extent, crack bridging. The influence of these mechanisms on fatigue crack propagation will, in certain cases, be altered by particle fracture during fatigue crack advance. As a result, the interaction between reinforcement particles and propagating fatigue cracks as well as the role of particle fracture in tensile failure have been of particular interest recently [2-14]. Fractographic studies have shown that particle fracture during fatigue crack propagation depends sensitively on maximum stress intensity $K_{\max }[2-6]$. The frequency of particle fracture is generally observed to be negligible at very small crack sizes and to increase monotonically with increasing $K_{\max }$, usually reaching a constant value at fast fracture [2-6]. In similar fractographic studies of particle fracture resulting from monotonic tensile fracture, the area fraction of fractured particles on the fracture surface has been observed to be numerically equal to the reinforcement volume fraction, leading to speculation that particle fracture during tensile failure is a random process $[5,7]$.

In the relatively few cases where particle fracture during fatigue crack growth was quantified $[2,4,8]$, SiC particle size was shown to have a pronounced effect on particle fracture. Shang et al. [2] found in their fatigue crack growth study of a powder metal 7XXX aluminium matrix composite that larger $\mathrm{SiC}_{\mathrm{p}}$ seemed to fracture preferentially at low $\Delta K$. Similarly, in a powder metal 6061 alloy with a bimodal distribution of SiC particles, Kumai et al. [4] found that the larger particles had a greater propensity for fracture. In other studies of cast and powder metal $6061-\mathrm{SiC}_{\mathrm{p}}[8,15]$, 
particle size was also seen to affect the frequency of particle fracture. These results are consistent with work reported by others, e.g. refs. 9 and 10, where the fracture of larger particles in $\mathrm{Al}-\mathrm{SiC}_{\mathrm{p}}$ composites was observed.

In addition, volume fraction and matrix aging condition significantly affected the frequency of particle fracture. Sugimura and Suresh [3] quantified particle fracture during fatigue crack growth in cast $\mathrm{Al}-3.5 \% \mathrm{Cu}$ reinforced with varying volume fractions of $\mathrm{SiC}_{\mathrm{p}}$ and found that the probability of particle fracture increased with increasing reinforcement volume fraction. They attributed this behavior to higher constraint levels in the matrix with increasing volume fraction. Lewandowski et al. [19] observed a noticeable difference in particle fracture based on the aging condition of a $7 \mathrm{XXX}$ aluminium alloy where the underaged material had a greater propensity of particle fracture than the overaged microstructure because of the lower matrix fracture strain in the overaged material.

While the propensity of $\mathrm{SiC}_{\mathrm{p}}$ to fracture during fatigue crack growth has been examined separately as a function of crack tip intensity [2-6], volume fraction [3] and particle size $[2,4]$, no published studies exist where all of these variables have been explored for the same alloy. In this paper we describe a study of the combined influences of particle size, volume fraction and matrix strength on the stress-controlled fatigue life in $2124 \mathrm{Al}$ reinforced with $\mathrm{SiC}_{\mathrm{p}}$ and on particle fracture during the fatigue crack growth portion of fatigue life. Detailed fractographic quantification of particle fracture during fatigue crack growth in these systems is presented and correlated with particle strength distributions and matrix properties in an effort to understand better the material parameters which control crack tip-particle interactions.

\section{Experimental procedure}

Supersolidus powder processed 2124 aluminium $(3.3 \% \mathrm{Cu}, 1.2 \% \mathrm{Mg})$ reinforced with 10,20 and 35 vol. $\%$ silicon carbide particles $\left(\mathrm{SiC}_{\mathrm{p}}\right)$ was evaluated in this study. Four different particle size distributions were also evaluated in the $20 \mathrm{vol} \%$ composite with average particle sizes of 2, 5, 9 and $20 \mu \mathrm{m}$. Average particle sizes in the $10 \mathrm{vol} \%$ and $35 \mathrm{vol} . \%$ composites were $12 \mu \mathrm{m}$ and $10 \mu \mathrm{m}$ respectively. All materials were supplied by DWA Composite Specialities Inc. as $13 \mathrm{~mm} \times 152 \mathrm{~mm}$ or $13 \mathrm{~mm} \times 76 \mathrm{~mm}$ extruded plates. Particle volume fractions were measured on a Leitz TAS Plus image analysis system and particle size distributions were measured manually from photomicrographs.
Cylindrical tensile and axial fatigue specimens, $5.5 \mathrm{~mm}$ diameter and $18 \mathrm{~mm}$ long gauge sections, were machined from the plates parallel to the extrusion direction in accordance to ASTM Specification E 46682. Specimens were solution heat treated in a salt bath at $495^{\circ} \mathrm{C}$ for $1 \mathrm{~h}$, water quenched and either naturally aged (NA) at room temperature for a minimum of $48 \mathrm{~h}$ or artificially aged for various times in oil at $190{ }^{\circ} \mathrm{C}$ to achieve underaged (UA), peak-aged (PA) and overaged (OA) conditions. Artificial aging times were determined experimentally for each composite material. Final machining and polishing steps were performed after heat treating.

Tensile tests were conducted using a screw-driven test machine at a displacement rate of $2 \mathrm{~mm} \mathrm{~min}^{-1}$. Fatigue tests were conducted using a servohydraulic materials test system under stress control with $R=-1$ and a frequency of $30 \mathrm{~Hz}$. Fatigue tests were terminated at complete separation of the specimen or after $10^{7}$ cycles were accumulated. Composite tensile and fatigue data were compared with unreinforced matrix alloy data. The matrix alloy was also produced by powder metal (PM) supersolidus compaction followed by extrusion.

Fractography of both tensile and fatigue specimens was performed with a CAMSCAN series 4 scanning electron microscope operated in secondary and backscattered electron modes. Chemical compositions of features at fatigue crack initiation sites were determined, where possible, using energy-dispersive spectroscopy in the scanning electron microscope at an operating voltage of $20 \mathrm{kV}$. Fracture surfaces were characterized in the scanning electron microscope at an operating voltage of $10 \mathrm{kV}$.

The area fraction of fractured $\mathrm{SiC}_{\mathrm{p}}$ on monotonic fracture surfaces was measured from an area at the center of each specimen. A montage of scanning electron microscopy (SEM) photomicrographs was made of each area and magnifications were selected so that the fractured particles would be approximately the same size on each montage, covering the equivalent area of approximately $1000 \mathrm{SiC}$ particles in a polished cross-section. Point counting using a square grid pattern (ASTM E 562-83) was used to determine the area fraction of fractured particles.

For the fatigue specimens, fractographic montages were constructed to evaluate the fatigue crack morphology from initiation to fast fracture. Area fractions of fractured particles were quantified in a similar manner as above. However, fatigue surface montages were $200-400 \mu \mathrm{m}$ in width and extended from the origin to the fast fracture region parallel to the crack propagation direction. Area fraction measurements were made on each photomicrograph and crack length was measured as the distance from the origin to the center 
of each photomicrograph. The data from two specimens per composite material were averaged for final analysis.

\section{Results}

The microstructures of all composites have relatively uniform particle distributions as shown in Fig. 1. Two examples of particle size distributions are also given in Fig. 1. It is noteworthy, in terms of the analyses to be described later, that a fairly broad particle size distribution existed, especially for the composites reinforced with larger particles.

Yield strength, tensile strength and tensile ductility are summarized in Table 1 for the materials examined in this study. In general, in the PA condition, yield and tensile strength increased with decreasing particle size and increasing volume fraction of reinforcement. For all but the largest particle size, the addition of $\mathrm{SiC}_{\mathrm{p}}$ reinforcement increases the yield and tensile strength of peakaged 2124 . In all cases, tensile ductility is significantly reduced with the introduction of reinforcement, with the lowest ductility found in the composite with the coarsest particle size. It can also be seen from Table 1 that aging condition can substantially affect tensile properties in the composites, indicating that matrix microstructure, as well as reinforcement, influences deformation in these materials.

The high cycle fatigue lives of the 2124 aluminium composites, shown in Figs. 2-4, were greater than those of the unreinforced matrix alloys for all stress levels tested with the exception of the $2124-\mathrm{SiC}_{\mathrm{p}}(20$ vol. $\%, 20 \mu \mathrm{m})$-PA. Although not shown, the fatigue life of the PM unreinforced matrix was greater than that for ingot material of similar composition and can be attributed to the finer grain size of the powder alloy. Further increases in fatigue lifetimes are seen with
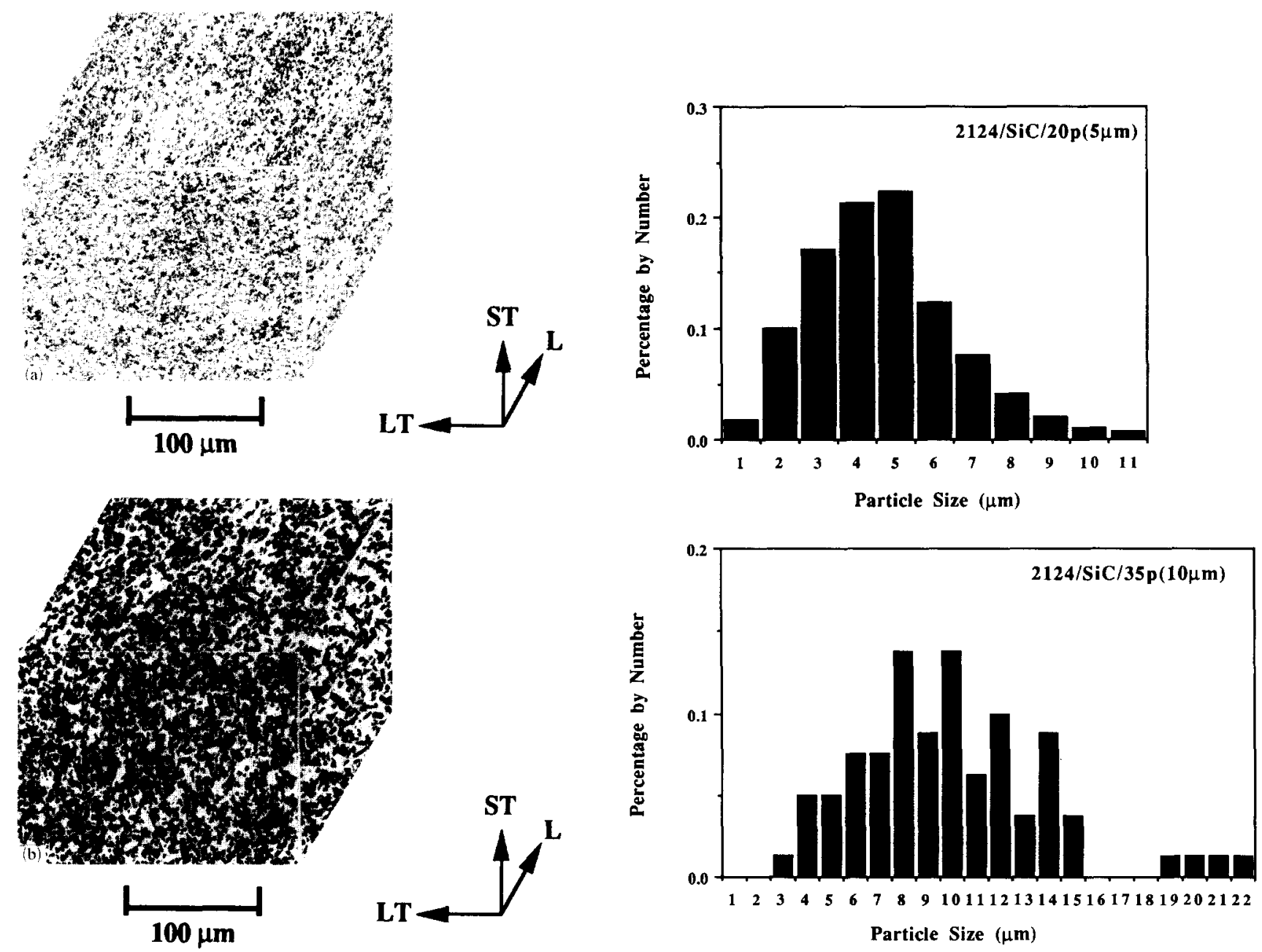

Fig. 1. Microstructures and particle distributions for (a) $2124-\mathrm{SiC}_{\mathrm{p}}(20 \mathrm{vol} . \%, 5 \mu \mathrm{m})$ and (b) $2124-\mathrm{SiC}_{\mathrm{p}}(35 \mathrm{vol} . \%, 10 \mu \mathrm{m})$. 
TABLE 1. Monotonic tensile properties of 2124-SiC

\begin{tabular}{|c|c|c|c|}
\hline Material & $\begin{array}{l}\text { Yield } \\
\text { strength } \\
\text { (MPa) }\end{array}$ & $\begin{array}{l}\text { Ultimate } \\
\text { tensile } \\
\text { strength } \\
\text { (MPa) }\end{array}$ & $\begin{array}{l}\text { Total } \\
\text { elongation } \\
(\%)\end{array}$ \\
\hline 2124-PA & 425 & 518 & 19.3 \\
\hline $2124-\mathrm{SiC}_{\mathrm{p}}(10$ vol. $\%, 12 \mu \mathrm{m})-\mathrm{PA}$ & 436 & 536 & 5.2 \\
\hline $2124-\mathrm{SiC}_{\mathrm{p}}(20$ vol. $\%, 2 \mu \mathrm{m})-\mathrm{PA}$ & 479 & 628 & 2.9 \\
\hline $2124-\mathrm{SiC}_{\mathrm{p}}(20$ vol. $\%, 5 \mu \mathrm{m})-\mathrm{PA}$ & 471 & 612 & 3.6 \\
\hline $2124-\mathrm{SiC}_{\mathrm{p}}(20$ vol. $\%, 9 \mu \mathrm{m})-\mathrm{PA}$ & 460 & 580 & 2.3 \\
\hline $2124-\mathrm{SiC}_{\mathrm{p}}(20 \mathrm{vol} . \%, 20 \mu \mathrm{m})-\mathrm{PA}$ & 425 & 500 & 2.2 \\
\hline $2124-\mathrm{SiC}_{\mathrm{p}}(35$ vol. $\%, 10 \mu \mathrm{m})-\mathrm{PA}$ & 460 & 600 & 2.9 \\
\hline $2124-\mathrm{SiC}_{\mathrm{p}}(20$ vol. $\%, 5 \mu \mathrm{m})-\mathrm{NA}$ & 423 & 608 & 3.7 \\
\hline $2124-\mathrm{SiC}_{\mathrm{p}}(20$ vol. $\%, 5 \mu \mathrm{m})-\mathrm{UA}$ & 436 & 586 & 2.6 \\
\hline $2124-\mathrm{SiC}_{\mathrm{p}}(20 \mathrm{vol} . \%, 5 \mu \mathrm{m})-\mathrm{OA}$ & 454 & 569 & 4.1 \\
\hline
\end{tabular}

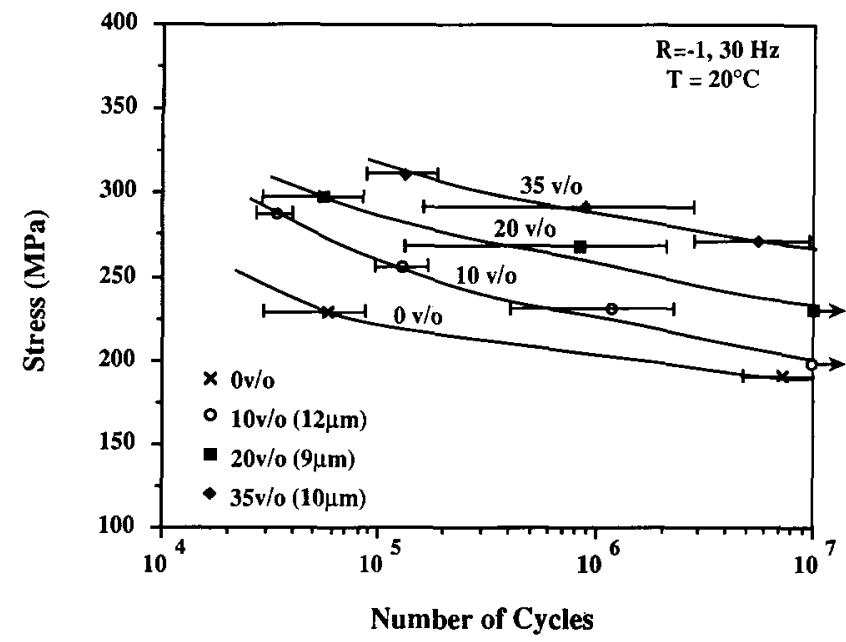

Fig. 2. Effect of volume fraction on fatigue life of $2124-\mathrm{SiC}_{\mathrm{p}}(9-12 \mu \mathrm{m})-\mathrm{PA}$.

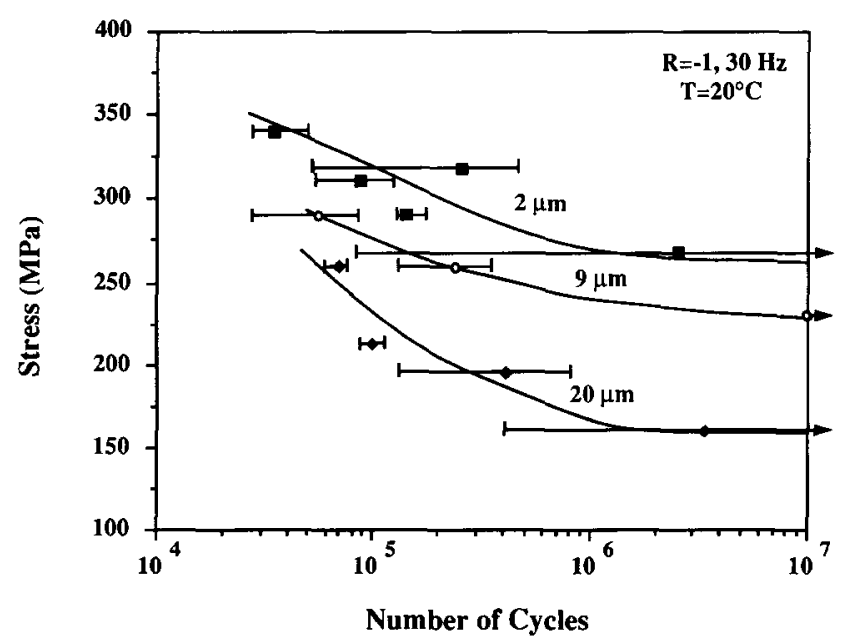

Fig. 3. Effect of particle size on fatigue life of $2124-\mathrm{SiC}_{\mathrm{p}}(20$ vol. \%)-PA.

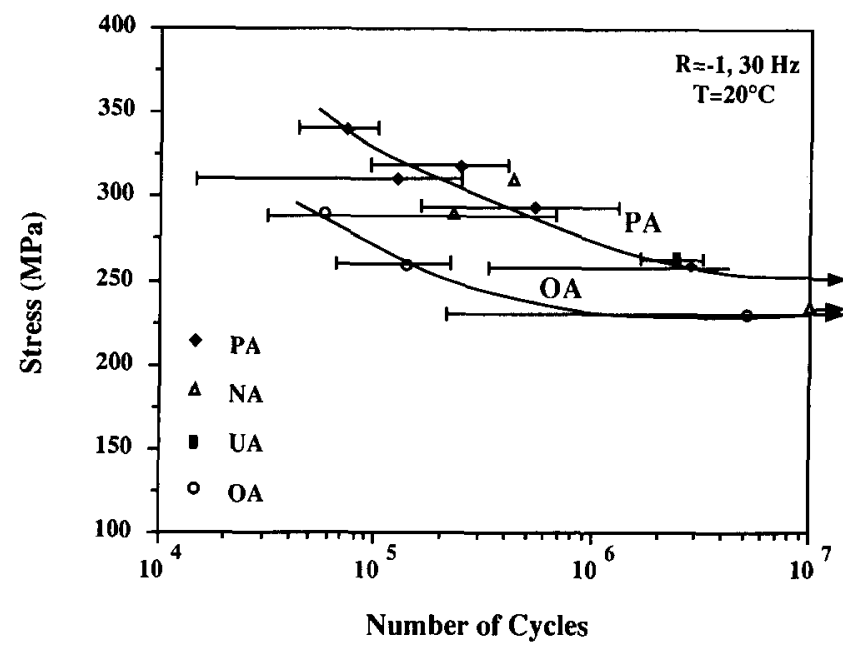

Fig. 4. Effect of aging on fatigue life of $2124-\mathrm{SiC}_{\mathrm{p}}(20 \mathrm{vol} \%$, $5 \mu \mathrm{m}$ ).
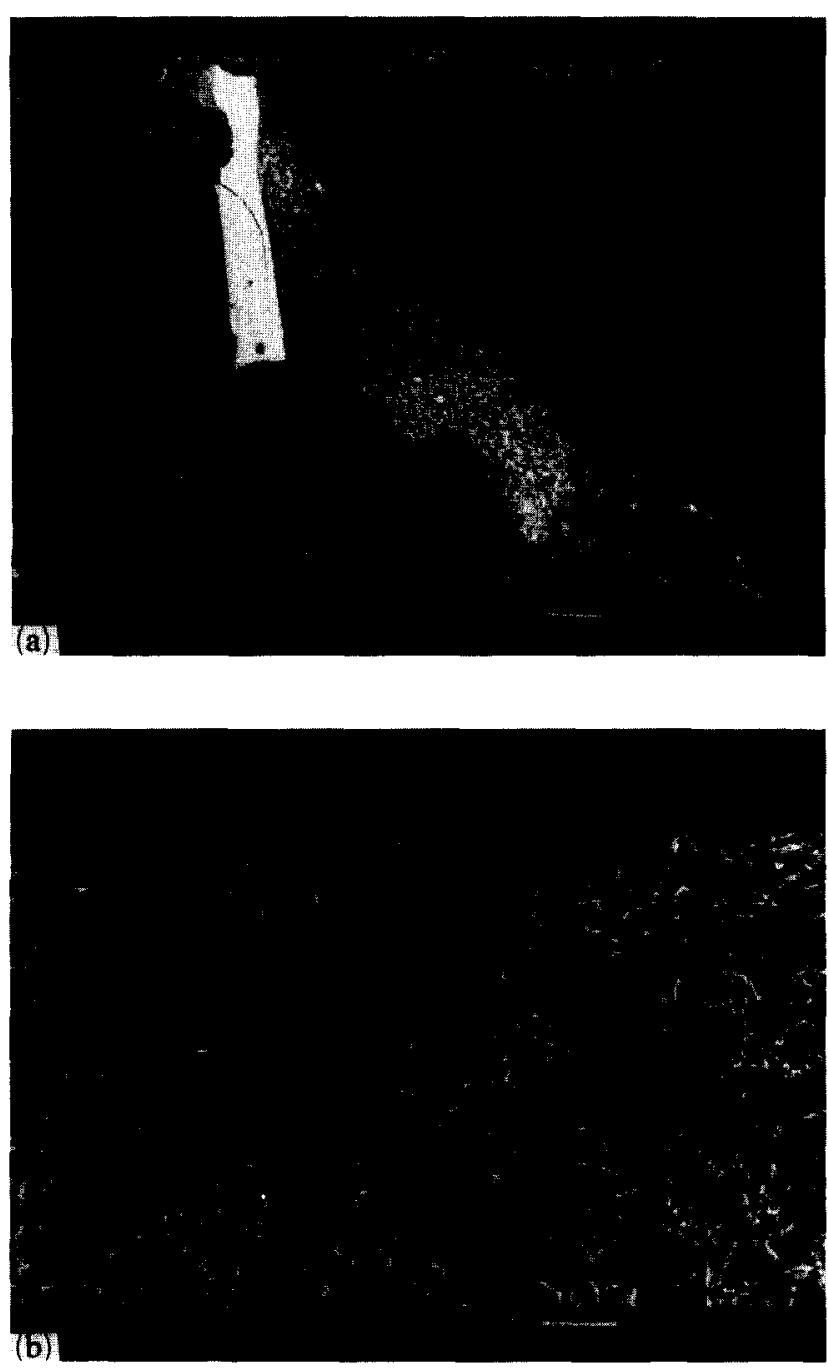

Fig. 5. Examples of fatigue crack initiation sites at (a) large intermetallic particle and (b) smaller $\mathrm{Mg}$ particle. 
increased $\mathrm{SiC}_{\mathrm{p}}$ volume fraction loading (Fig. 2), decreased particle size (Fig. 3), and increased matrix strength (Fig. 4). The data in Figs. 2-4 show the range and averages of lifetimes for three to four specimens per stress level. Run-out specimens were assigned lifetimes of $10^{7}$ cycles.

A majority of the fatigue crack initiation sites were single intermetallic particles (iron or copper rich), $10-80 \mu \mathrm{m}$ in maximum length. In some cases, initiation occurred at particle clusters, as large as $100 \mu \mathrm{m}$, and in a few samples initiation sites were unidentifiable. In all cases no multiple initiation sites were observed and initiation was generally near the specimen surface (usually within $10 \mu \mathrm{m}$ ). The variability in size of the inclusions or particle clusters, especially those of $50 \mu \mathrm{m}$ or more at which fatigue cracks initiated, appears to be the main contribution to the large amount of scatter in fatigue. An example of one of the large intermetallic particles is shown in Fig. 5 together with one of the smaller intermetallic particles. For the $2 \mu \mathrm{m}$ particle composite, a large initiation site, such as in Fig. 5(a), made the difference in lifetime between approximately 80000 cycles and run-out at $10^{7}$ cycles.

Examination of fracture surfaces revealed differences in crack path behavior between tensile and fatigue fractures and between different composite materials. Tensile fracture surfaces displayed many fractured $\mathrm{SiC}$ particles uniformly distributed across the surfaces while fatigue fractures exhibited increasing amounts of particle fracture from crack initiation to fast fracture. In the immediate area surrounding the fatigue crack initiation site no fractured particles were found. The fatigue fracture surface in this area has a relatively flat, featureless matrix morphology with no
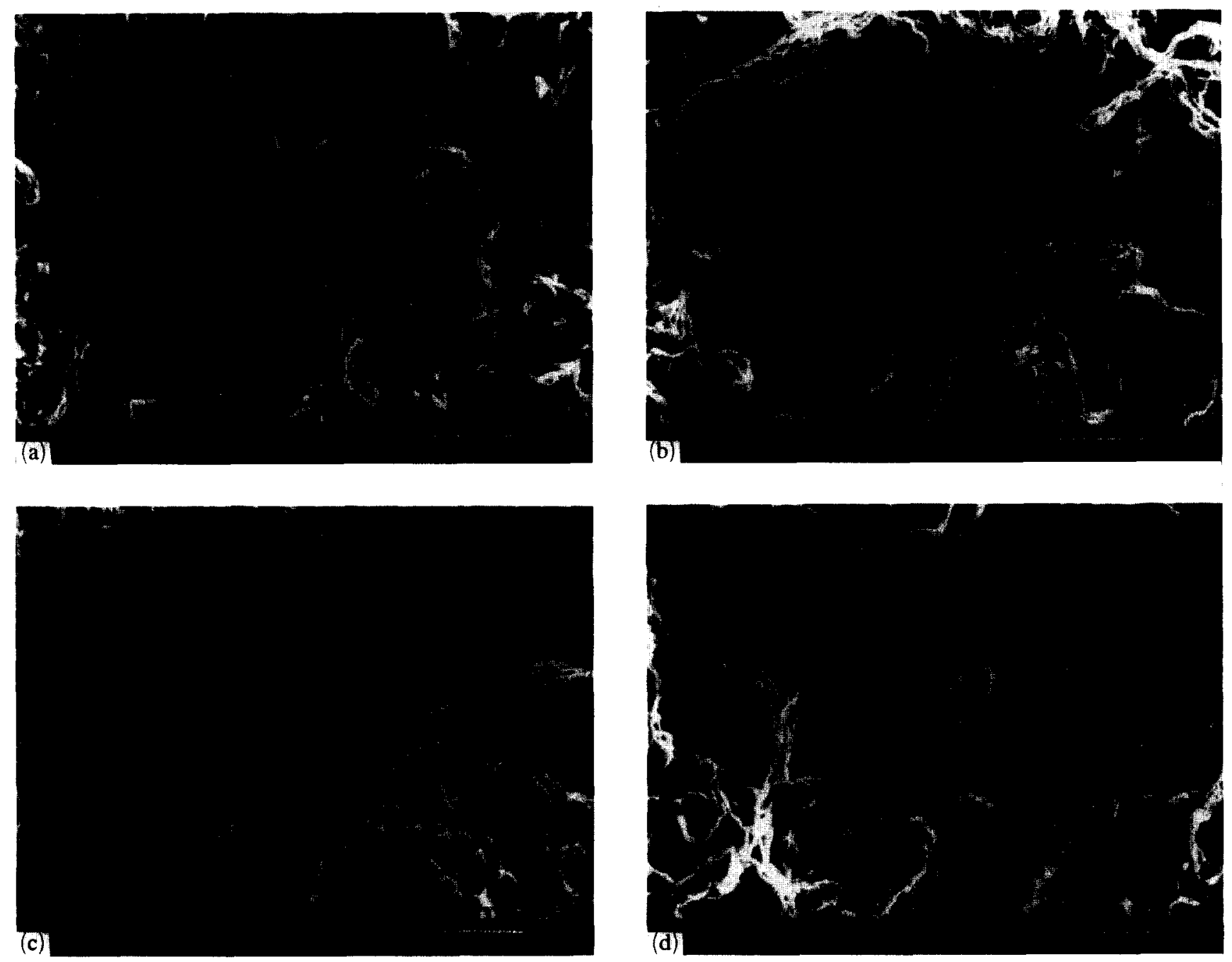

Fig. 6. Typical fracture surfaces for $(\mathrm{a})$ low $K_{\max } \approx 4 \mathrm{MPa} \mathrm{m}^{1 / 2}\left(A_{\mathrm{f}}=0.01\right),(\mathrm{b})$ intermediate $K_{\max } \approx 10 \mathrm{MPa} \mathrm{m}^{1 / 2}\left(A_{\mathrm{f}}=0.04\right),(\mathrm{c})$ fatigue fast fracture $\left(A_{\mathrm{f}}=0.12\right)$ and $(\mathrm{d})$ monotonic tensile fracture $\left(A_{\mathrm{f}}=0.14\right)$. 
apparent fatigue striations (Fig. 6(a)). With increasing distance from the origin, the occurrence of fractured particles increased (Fig. 6(b)) until, at fast fracture, the amount of fractured particles remained essentially constant. The frequency of particle fracture measured in the fast fracture regime (Fig. 6(c)) is approximately the same as that measured on monotonic tensile fractures (Fig. 6(d)). Fractured particles appear relatively dark and flat and often exhibit cleavage on their surfaces. The matrix surrounding the particles shows microvoid coalescence.

The variation in amount of particle fracture as the crack grows from initiation to fast fracture and between the different composite materials is shown in Fig. 7 where the probability of particle fracture is plotted against maximum crack tip stress intensity. The probability of particle fracture is measured as the area fraction of fractured particles normalized for volume fraction loading. The solution for maximum crack tip stress intensity $K_{\max }$ is that of Raju and Newman [16]

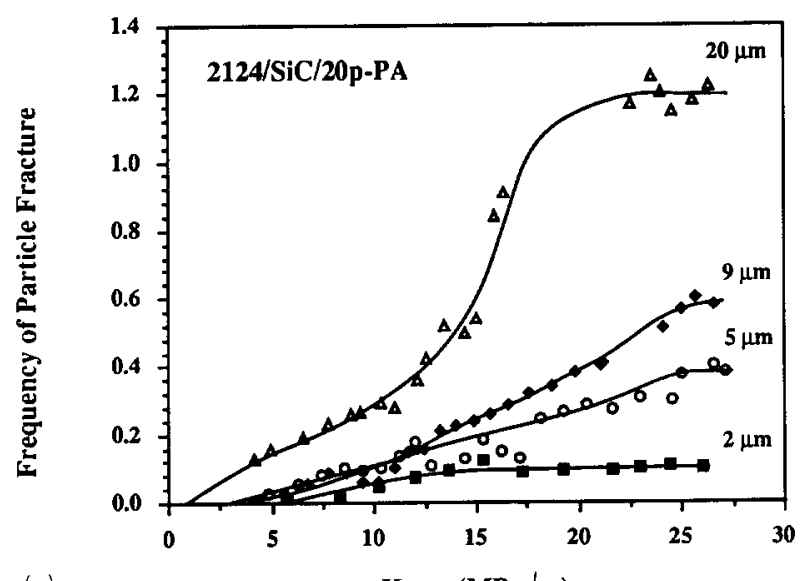

(a)

$K_{\max }\left(\mathrm{MPa} V_{\mathrm{m}}\right)$

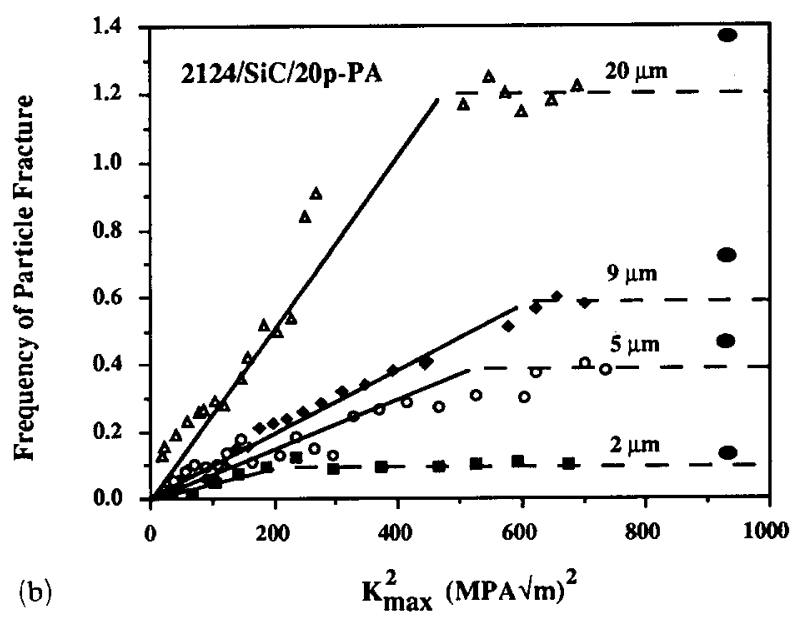

Fig. 7. Effect of particle size on frequency of particle fracture (a) as a function of $K_{\max }$ and (b) as a function of $K_{\max }{ }^{2}$. derived for semielliptical surface cracks in cylindrical bars. Figure $7(a)$ clearly shows that particle fracture increases as $K_{\max }$ increases until a maximum level of fracture is reached. This maximum level of particle fracture is not the same for all composites.

Process zone size has also been discussed as affecting the amount of particle fracture $[2,5]$. If particle fracture is influenced by process zone size then the probability of fracture should scale linearly with $K_{\max }{ }^{2}$. Figures $7(\mathrm{~b}), 8$ and 9 show the probability of particle fracture as a function of $K_{\max }{ }^{2}$ for different particle sizes, volume fractions and matrix strengths and a good linear fit is observed in all cases. In addition, the probability of particle fracture in the fast fracture regime agrees with that for tensile fracture (indicated by full ovals).

Figure 7 also shows the effect of particle size on the probability of particle fracture, with the frequency of particle fracture increasing as particle size increases. Although the particle fracture data for the 10 and $20 \mathrm{vol} . \%$ composites make it impossible to distinguish a volume fraction effect on the probability of particle fracture, as shown in Fig. 8, the 35 vol.\% composite clearly exhibits a greater propensity for particle fracture over the other two volume fraction loadings. The probability of particle fracture also increases somewhat with increasing matrix strength (Fig. 9). The data shown in these figures are the averages of measurements from two specimens for each composite material.

In summary, the data show that increasing particle size and volume fraction, and to some degree increasing matrix strength, increase the probability of particle fracture. The influence of matrix strength on particle fracture is more clearly demonstrated when comparing matrix strengthening through alloying. Figure 10 shows

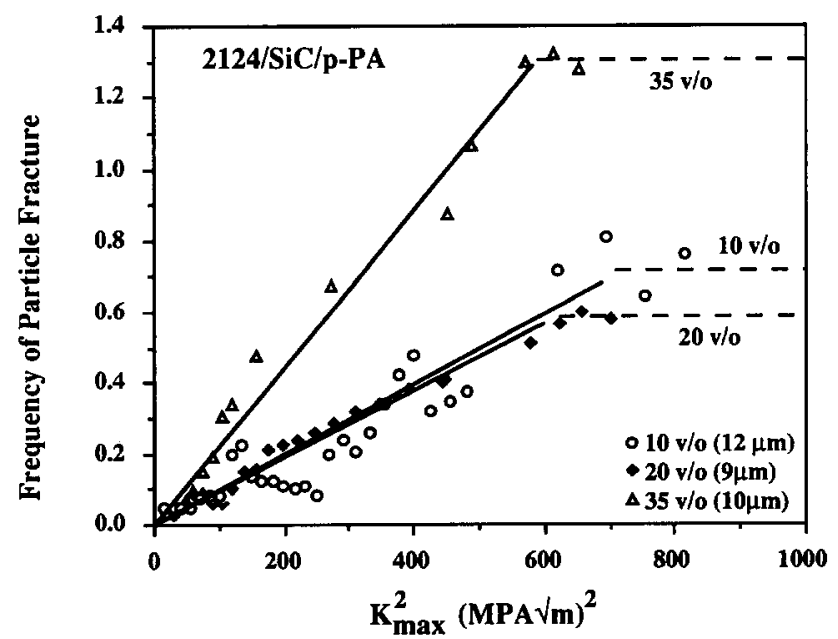

Fig. 8. Effect of volume fraction on frequency of particle fracture. 


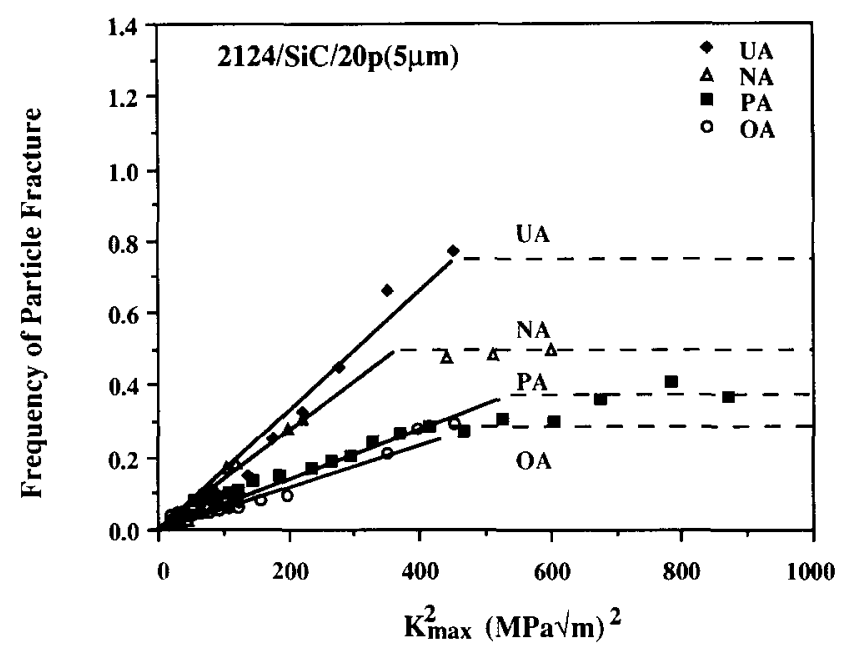

Fig. 9. Effect of aging on frequency of particle fracture.

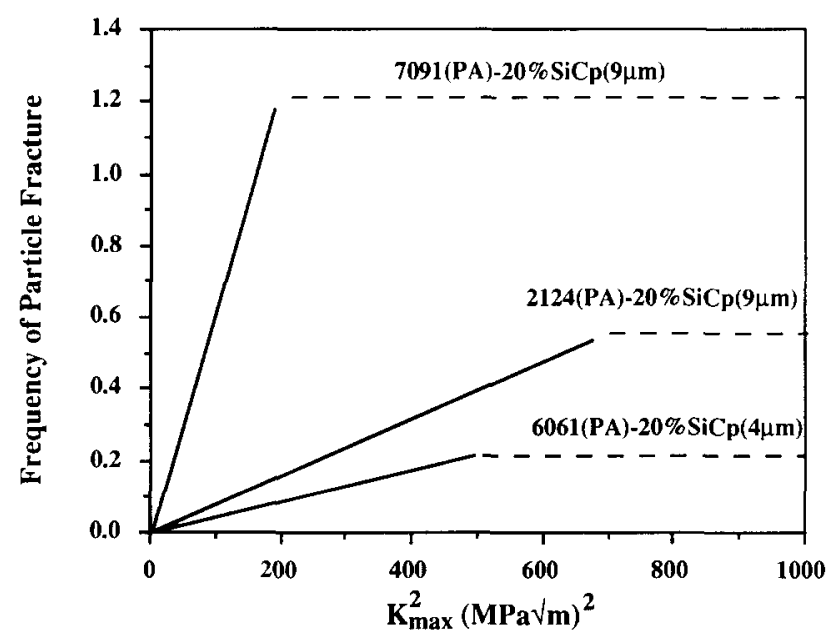

Fig. 10. Effect of alloying on frequency of particle fracture.

the comparison of 2124, 6061 [15] and 7091 [17] PM $\mathrm{Al}$ alloys peakaged and reinforced with 20 vol. $\% \mathrm{SiC}_{\mathrm{p}}$ with similar particle sizes. The higher strength 7091 alloy has a much greater propensity for particle fracture than the lower strength 2124 and 6061 alloys.

\section{Discussion}

In the previous section, it was demonstrated that particle size, volume fraction and matrix strength influence the probability of particle fracture during fatigue crack propagation. It was also shown that particle fracture is strongly dependent on crack tip stress intensity and, in particular, on some measure of the crack tip plastic zone or process zone, as revealed by the $K_{\max }{ }^{2}$ dependence of particle fracture. The most probable reasons for these observations are reviewed in this section.

\subsection{Strengthening}

Increased yield and tensile strengths in $\mathrm{SiC}_{\mathrm{p}}-$ reinforced 2124 aluminium alloy were found with increased particle volume fraction, decreased particle size and increased matrix strength. These findings are consistent with the data of others on composite strengthening in $\mathrm{Al}-\mathrm{SiC}_{\mathrm{p}}$ composites where strength was increased through the addition of $\mathrm{SiC}$ particles to an aluminium matrix $[7,18]$ and further increases were observed with increased particle volume fraction and decreased particle size [19-21].

Strengthening mechanisms for particle-reinforced metal matrix composites can result from load transfer to the reinforcement, reinforcement-induced changes in the matrix microstructure or matrix constraint. Strengthening through load transfer has been described using modified shear lag models $[22,23]$ and using the Eshelby model [24]. These continuum models predict increases in strength with increased volume fraction, particle aspect ratio and matrix yield strength. Changes as a result of particle size are not accounted for in these models. Evans et al. [25] claim particle size affects ultimate tensile strength and work hardening but not yield strength. Although claims have been made that the particle aspect ratio is too small for stress transfer, the elastic modulus in particle-reinforced composites is increased, implying that load transfer does occur [26].

Strengthening through changes in the matrix microstructure as a result of the addition of particles has been reported to occur through the combination of several mechanisms including coefficient of thermal expansion (CTE) mismatch, grain and subgrain refinement, increased work hardening and change in precipitate strengthening [19-21, 27]. A significant increase in tensile strength is observed (Table 1) when grain size is decreased when comparing PM aluminium alloy matrices with traditionally cast and extruded alloys [28]. Although grain size is further refined with the addition of $\mathrm{SiC}$ particles, this has little additional effect on strengthening. The increases in tensile strengths of the composites have been argued to be mainly the result of the increase in dislocation generation because of the CTE mismatch between the matrix and the reinforcement and dislocation pile-ups at particle-matrix interfaces $[19,27]$. The increased dislocation density in the composite provides additional precipitate nucleation sites, thus accelerating the aging process [29]. Therefore, the increased number of barriers impeding dislocation motion, through increased grain and subgrain boundaries, dislocation density and precipitates and the presence of $\mathrm{SiC}_{\mathrm{p}}$ are also argued to provide a 
significant contribution to strengthening [20,21]. Both of these strengthening effects are amplified with increased volume fraction and decreased particle size which provide greater matrix-particle boundary area and decreased particle spacing.

More recently, finite element analyses of these materials have considered reinforcement geometry, spatial distribution and failure mechanisms, such as particle fracture [30-33], on strength. Although geometry has a significant influence on strength through load transfer, spatial distribution as affected by volume fraction or clustering significantly influenced strength through matrix constraint [30-32]. However, subsequent fracture of the reinforcement reduced constraint $[32,33]$.

Finally, Wu and Lavernia [34] propose a combination of load transfer and matrix changes for strengthening where each mechanism contributes to strength in proportion to its volume fraction. It is well known that increased reinforcement volume fraction increases modulus in $\mathrm{Al}-\mathrm{SiC}_{\mathrm{p}}$ composites, thus having some strength effect as a result of continuum mechanics. However, this study also reveals a yield stress dependence on particle size which shows that matrix strengthening must also be operative.

\subsection{Fatigue behavior}

Stress-controlled fatigue lives of $2124 \mathrm{Al}-\mathrm{SiC}_{\mathrm{p}}$ were shown to increase with decreased particle size, increased volume fraction and increased matrix tensile strength for a given stress level. The influence of particle size and volume fraction on fatigue strength is consistent with their influence on monotonic tensile strengths discussed above. It has been frequently reported in the literature that fatigue lives of composites tested in stress control are generally longer than their unreinforced counterparts [35-39]. This has often been attributed to the higher strength levels observed in composite materials over the unreinforced matrix alloy. Holcomb [40] also demonstrated increases in stress-controlled fatigue lives with increased volume fraction and decreased particle size in $\mathrm{SiC}$ particle reinforced 2014 aluminium alloy.

Correlation of fatigue strength with monotonic tensile strength is often seen for monolithic alloys and has also been shown in metal matrix composites such as cast aluminium alloys reinforced with Saffil $\left(\mathrm{Al}_{2} \mathrm{O}_{3}\right)$ fibers $[35,41]$ and PM aluminium alloys reinforced with $\mathrm{SiC}$ whiskers $[18,42]$. When tensile strengths of the composites were increased, fatigue strengths, derived from stress-controlled tests, were also increased. However, an exception to this was found by Bonnen et al. [5]. Their results reveal an increase in fatigue life without an increase in tensile strength of a composite over its unreinforced matrix alloy. The increased fatigue life was attributed to the increased modulus (decreased strain at a given stress) of the composite. Modulus and strength contributions to fatigue life in stress-controlled testing can be separated in the present study and only composite tensile strength was found to have a significant effect. For the range of particle sizes studies in the $20 \mathrm{vol} \%$ materials, there was no change in modulus. However, tensile strength and fatigue life both increased with decreasing particle size. In addition, for $2124-\mathrm{SiC}_{\mathrm{p}}(20 \mathrm{vol} . \%, 2 \mu \mathrm{m})-\mathrm{PA}$ and $2124-\mathrm{SiC}_{\mathrm{p}}(35 \mathrm{vol} . \%, 10 \mu \mathrm{m})$-PA with nearly identical tensile strengths, but significantly different moduli, fatigue lives were equivalent. If modulus does play a role in fatigue life, it must be offset by the amount of particle fracture $[32,33]$. It is also important to note that increased monotonic strength typically leads to decreased fatigue crack propagation resistance which put a greater emphasis on fatigue crack initiation life to achieve longer fatigue lives.

Fatigue crack initiation sites were predominantly large intermetallic particles located near the specimen surface, although in a few specimens cracks initiated at small clusters of $\mathrm{SiC}$ particles. The presence of such large intermetallic particles is the result of agglomeration of constituent particles during the supersolidus processing. It is thought that these large particles initiate fatigue cracks prematurely (by evidence of single origins and large scatter in $S-N$ data especially at low stress levels), also shown by Williams and Fine [42], and that fatigue crack initiation lifetime might be delayed if the intermetallic particles could be reduced in size or eliminated (in the case of iron-based inclusions). In subsolidus processed PM A1 composites, large intermetallic particles have not been observed as dominant initiation sites. Bonnen et al. [5] found multiple initiation sites in $2 \mathrm{XXX}-\mathrm{SiC}_{\mathrm{p}}(15 \mathrm{vol} \% \mathrm{\%})-\mathrm{T} 4$ at particle clusters, intermetallic particles and others, none of which appeared to affect fatigue life. However, very few initiation sites in their study were found to be greater than $50 \mu \mathrm{m}$ which appeared to be the critical size which had a systematic effect on lifetime in this study. Interestingly, these larger sites yielded stress intensity values greater than $\Delta K_{\text {th }}$ levels reported by Davidson [43].

\subsection{Reinforcement particle fracture}

The nature of particle fracture has been examined for monotonic tensile fracture, fatigue crack propagation and unstable crack propagation at the termination of fatigue. The results show that the amount of particle fracture increases with decreased particle size, increased volume fraction and increased matrix strength. In addition, during fatigue crack propagation the frequency of particle fracture increases with increasing stress intensity. 
The observations of reinforcement particle fracture area, in general, supported by the findings of previous studies. For example, the increase in particle fracture with increasing stress intensity during fatigue crack propagation, as shown in Fig. 7, was also observed by Shang et al. [2], Sugimura and Suresh [3], and Kumai et al. [4] and in stress-controlled fatigue studies by Bonnen et al. [5] and Hall et al. [15, 17]. A preference for fracture of larger particles was also observed in fatigue crack growth studies by Shang et al. [2] at low $\Delta K$ in $7091 \mathrm{Al}$ reinforced with $20 \% \mathrm{SiC}$ particles with average sizes of 6 and $10 \mu \mathrm{m}$. Kumai et al. [4] studied bimodal particle distributions in $6061 \mathrm{Al}$ with $15 \%$ and $30 \% \mathrm{SiC}$ particles and also found that the larger particles exhibited a greater frequency of fracture. The influence of volume fraction on particle fracture during fatigue crack growth was studied by Sugimura and Suresh [3] in $\mathrm{Al}-3.5 \mathrm{Cu}$ with $6 \%, 13 \%$ and $20 \% \mathrm{SiC}$ particles and Kumai et al. [4] in $6061 \mathrm{Al}$ with $15 \%$ and $30 \% \mathrm{SiC}$ particles. Their results indicated that particle fracture was more prevalent in composites with larger volume fractions, in agreement with the present observations (Fig. 8). Although the effect of matrix strength on particle fracture during fatigue crack growth has been given no direct comparison in the literature, since most studies have been confined to one alloy, a comparison of the collective results of Shang et al. [2], Sugimura and Suresh [3] and Kumai et al. [4] supports the finding in the present study that increasing matrix strength increases the amount of particle fracture.

Although the qualitative nature of reinforcement particle fracture during fatigue or monotonic fracture is now well documented, the task of modelling the fracture process in terms of particle strength and the particle stresses developed during crack advance remains. However, the results of these studies indicate that fracture in brittle $\mathrm{SiC}$ particles in metallic matrices can be reasonably described using a weakest link approach. Weakest link theory has been used previously to describe fracture of brittle particles in ductile matrices under monotonic loading. Using this approach, Evans [44] and Lin et al. [45] have successfully described the fracture of iron carbide particles in the plastic zone of monotonically loaded cracks in steel. They conclude that the predicted decrease in fracture toughness with increased carbide particle size is a result of lower particle strength and the increased likelihood of particle fracture in the crack tip region. Wallin et al. [46] examined the probability of particle fracture for a population of copper oxide particles in a copper matrix under monotonic tensile loading and found the probability of fracture increased as $d^{3}$, where $d$ is the particle diameter. These studies are based on the assumption that particle fracture is stress controlled and particle fracture strength is inversely proportional to particle size.

Before a rigorous model for particle fracture in SiC reinforced alloys can be completed it will be necessary to have accurate descriptions of particle strength distributions and accurate assessments of particle stresses as a function of particle size and shape, particle clustering and matrix deformation properties. While substantial progress is currently being realized in the latter area $[30,47]$, the issue of particle strength is still unresolved. In spite of the lack of specific information, it is still possible to test the weakest link concept using the particle fracture data from the present study.

Particle strength can be estimated by analysis of particle fracture under monotonic loading if it is assumed that the particle distribution is a scalar function of the particle size distribution and that the maximum stresses developed in the reinforcement particles can be approximated by a rule-of-mixtures approach for composite tensile strength where it is assumed that the matrix will fail when loaded to its unreinforced tensile strength and that the particles will carry the additional load. The latter assumption neglects elevation of matrix tensile strength by the addition of reinforcement, and, therefore, particle stresses are probably overestimated. Particle fracture strength is coupled with particle size by comparing the average stress on a particle with the amount of fractured particles. To extract this from measurements of composite tensile strength and area fraction of fracture particles, the approach illustrated schematically in Fig. 11 is used. Figure 11(a) shows a schematic of a distribution of the number of particles by their maximum length, as found in a polished crosssection. In the present study, the propensity for SiC particles to fracture was measured by area and, therefore, the size distribution of particles is more appropriately compared by particle area fraction as shown in Fig. 11(b). Since particle strength is assumed to scale inversely with particle size, these distribution curves also give particle strength distributions. Measured particle fracture area fractions are superposed on the areal distribution, as shown in Fig. 11(b), and the minimum particle size at the lower bound of this area is assigned the average applied stress as its fracture strength, implying that particles smaller than this size will not fracture and those larger will.

Using this approach particle fracture strengths were calculated from tensile tests for all materials in this study. The results are plotted in Fig. 12 together with results from an identical analysis of 6061 composites from a previous study [15]. The data shown in Fig. 12 clearly demonstrate the inverse relationship of particle strength to size which is consistent with the findings for 

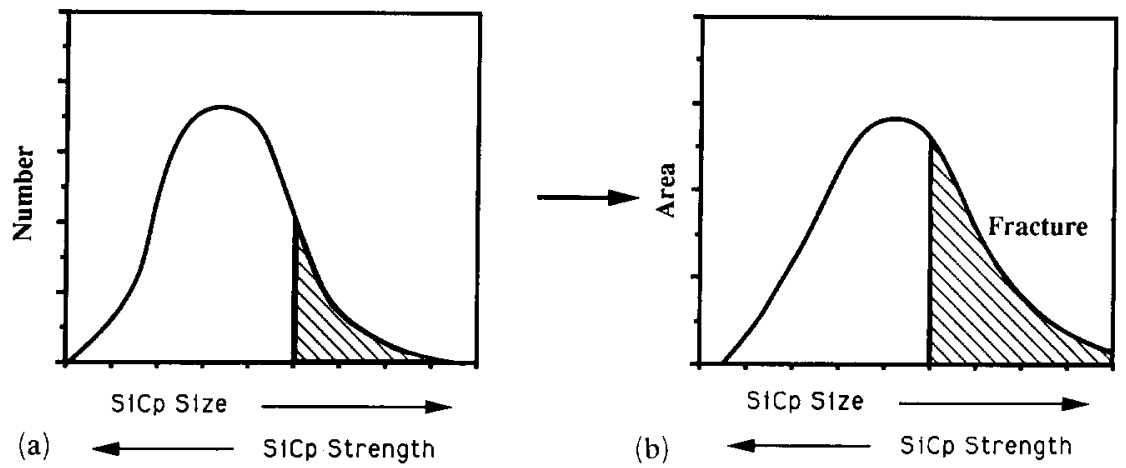

Fig. 11. Example of typical SiC particle size distribution by (a) number and (b) area. Shaded area indicates measured amount of particle fracture.

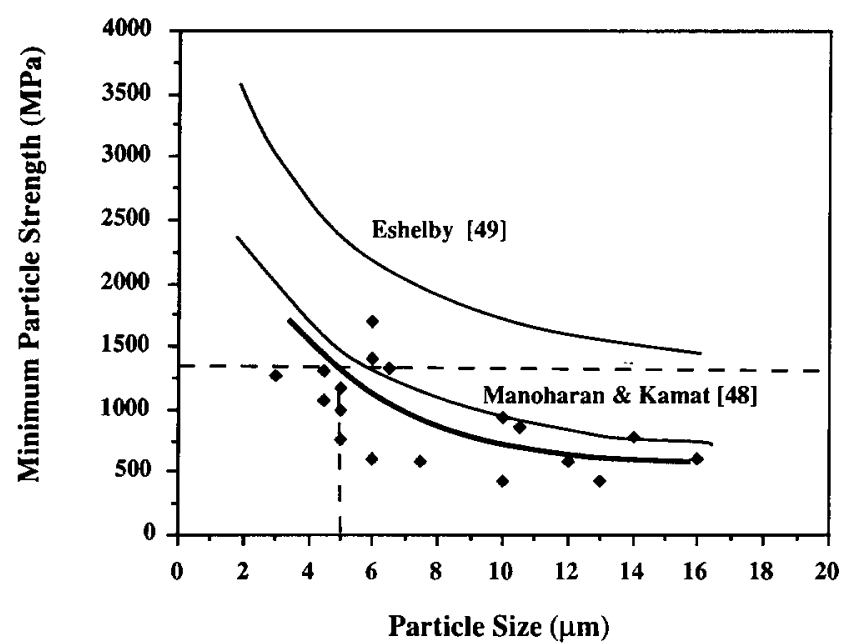

Fig. 12. Particle strength as a function of particle size derived from tensile data.

iron carbides $[44,45]$ and copper oxide particles [46]. Good agreement was found with strength data reported by Manoharan and Kamat [48] who measured $\mathrm{SiC}_{\mathrm{p}}$ strength using a fracture mechanics approach where fracture was assumed to occur when the combination of particle stress and defect size reach the fracture toughness for $\mathrm{SiC}$. Their results are extended here by assuming a constant defect-to-particle size ratio and are shown in Fig. 12. In addition, an approximation of the stress field induced in and around a particle is also given using the Eshelby model [49]. The fact that the theoretical stress level in the particles is significantly higher than particle fracture strengths approximated in the present study is consistent with defect-controlled particle fracture.

In order to extend this approach to particle fracture resulting from unstable crack propagation, as in the case of specimen failure at the end of fatigue life, it is necessary to consider the near-crack-tip stress distribution. An approximation of this stress distribution and the maximum crack tip stresses can be obtained from the HRR solution for small-scale yielding [50, 51]. For example, in NA 2124 a maximum crack tip stress of 1350-1540 MPa, estimated from 3.5-4.0 times the matrix yield strength ( $385 \mathrm{MPa}$ ) for moderately low strain hardening material, is obtained from the HRR solution. From Fig. 12, a fracture stress of $1450 \mathrm{MPa}$ corresponds to a critical particle size for particle fracture of $4.5 \mu \mathrm{m}$. Thus, from the approach outlined in Fig. 11 a composite with a normal particle distribution and a mean particle size of $4.5 \mu \mathrm{m}$ would be expected to exhibit a particle fracture area on the composite fracture surface of $50 \%$, which is the value determined experimentally in naturally aged $2124-\mathrm{SiC}_{\mathrm{p}}(20 \mathrm{vol} . \%)$ with an average particle size of $5 \mu \mathrm{m}$, as shown in Fig. 9.

These results, although approximate, indicate that maximum crack tip stress, in addition to particle strength (size), determines the probability of particle fracture. Thus, particle fracture during unstable crack propagation will also depend on the strain hardening behavior of the matrix. For example, PA 2124 exhibits a lower strain hardening rate than the same alloy in the UA condition and from the HRR solution should have a lower maximum crack tip stress. As expected, in the $2124-\mathrm{SiC}_{\mathrm{p}}(20 \mathrm{vol} . \%, 5 \mu \mathrm{m})$-PA composite a lower amount of particle fracture was observed, $38 \%$ vs. $50 \%$, in the PA condition compared with the NA condition. Similarly, in fracture toughness studies by Lewandowski et al. [10] the amount of $\mathrm{SiC}$ particle fracture was evaluated in a $7 \mathrm{XXX}-\mathrm{SiC}_{\mathrm{p}}(20$ vol. $\%)$ composite in UA and OA conditions to similar yield strengths. Their results showed that the UA condition with a greater strain hardening rate had significantly more fractured particles than that observed for the OA condition. It should be noted, however, that the simplified approach of using unreinforced matrix deformation behavior to predict crack tip stresses in composites does not account for the influence of volume fraction at constant particle size on the probability of particle fracture. This is illustrated for the 
case of $2124-\mathrm{SiC}_{\mathrm{p}}(35$ vol. $\%, \quad 10 \mu \mathrm{m})-\mathrm{PA}$ and $2124-\mathrm{SiC}_{\mathrm{p}}(20 \mathrm{vol} . \%, 9 \mu \mathrm{m})-\mathrm{PA}$, where the probability of particle fracture is significantly larger in the higher volume fraction material, although the particle strength distribution is presumably the same in both materials. This difference can be attributed to the elevation of matrix yield strength in the higher volume fraction material as a result of increased constraint [ 30 , 32] from the more closely spaced particles.

Finally, it is necessary to explain the observed dependence of particle fracture on maximum stress intensity during fatigue crack propagation. The solutions for maximum crack tip stress used here are independent of crack tip stress intensity. However, the $K_{\max }{ }^{2}$ dependence of particle fracture, as shown in Figs. 7-10, suggests that the plastic zone or process zone size is important, as well, in transferring sufficient stress to cause particle fracture. This is illustrated in Fig. 13 where, in early crack growth, the plastic zone size and, correspondingly, the region of maximum stress is quite small and on the order of the particle size. Effective stress transfer to the particles cannot occur and the crack is deflected from the particle in the manner described by Suresh et al. [52] for a crack approaching a phase boundary where the second phase has higher strength and modulus. However, as the crack propagates and the plastic zone increases in volume, it can more effectively transfer stress to these particles with the result that particle fracture will eventually reach a constant value, dependent on particle strength and maximum crack tip stress, as described previously. Further studies are required to develop a more complete understanding of crack tip stresses and particle fracture and these will require incorporation of the effects of reinforcement on crack tip stresses. For example, Kim et al. [53] have shown that the presence of particles reduces plastic zone size over that predicted for monolithic alloys.

\section{Conclusions}

The effects of particle size, volume fraction and matrix strength on particle fracture during monotonic tensile fracture, fatigue crack propagation and unstable
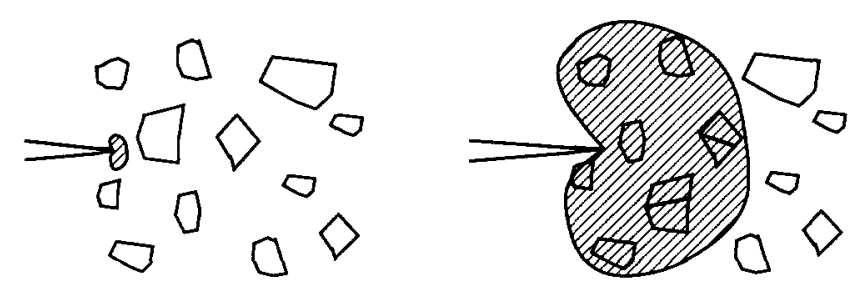

Fig. 13. Schematic of plastic zone size showing larger plastic zone sampling increased number of particles. crack propagation were studied in $2124-\mathrm{SiC}_{\mathrm{p}}$ composites. The conclusions from this study are as follows.

(1) Tensile and yield strengths were increased over the unreinforced matrix alloy with the addition of $\mathrm{SiC}$ particles. Additional increases were observed with decreased reinforcement particle size and increased particle volume fraction.

(2) Increases in fatigue lives were consistent with increases in tensile strengths as observed in monolithic alloys. Fatigue cracks initiated at large intermetallic inclusions or constituent particles and clusters of $\mathrm{SiC}$ particles, typically near the specimen surface. Fatigue lives were relatively independent of initiation characteristics, except for larger particles or cluster.

(3) Increased particle fracture with increased $\mathrm{SiC}_{\mathrm{p}}$ size and volume fraction and increased matrix strength is consistent with the weakest link approach where particle strength is dependent on particle size.

(4) Increased particle fracture with increased crack tip stress intensity was shown to be a result of increased plastic zone size which sampled a statistically greater number of particles.

\section{References}

1 J. E. Allison and J. W. Jones, in S. Suresh, A. Mortensen and A. Needleman (eds.), Fundamentals of Metal Matrix Composites, Butterworth-Heinemann, 1993.

2 J. K. Shang, W. Yu and R. O. Ritchie, Mater. Sci. Eng. A, 102 1988) 181.

3 Y. Sugimura and S. Suresh, Metall. Trans. A, 23 (1992) 2231.

4 S. Kumai, J. E. King and J. F. Knott, Fatigue, Fract. Eng. Mater. Struct., 13(1990) 511.

5 J. J. Bonnen, J. E. Allison and J. W. Jones, Metall. Trans. A, 22 (1991) 1007.

6 C. P. You and J. E. Allison, in K. Salarma (ed.), Int. Conf. on Fracture-7, 1989, Pergamon, Oxford, 1989, p. 3005.

7 C. P. You, A. W. Thompson and I. M. Bernstein, Scr. Metall. $2 I(1987) 181$.

8 D. J. Lloyd, Acta Metall. Mater., 39 (1991) 59.

9 D. L. Davidson, Metall. Trans. A, 22 (1991) 97.

10 J. J. Lewandowski, C. Liu and W. H. Hunt, Jr., Mater. Sci. Eng. A, 107 (1989) 241.

11 J. K. Shang and R. O. Ritchie, Mater. Sci. Eng. A, 102 (1988) 181 .

12 T. J. Downes, D. M. Knowles and J. E. King, in D. Finao (ed.), Fracture Behaviour and Design of Materials and Structures, Engineering Materials Advisory Services, Cradely Heath, 1990.

13 C. Liu and J. J. Lewandowski, in D. S. Wilkinson (ed.), Advanced Structural Materials, Pergamon, Oxford, Vol. 9, 1988 , p. 23.

14 D. L. Davidson, Metall. Trans. A, 18 (1987) 2115.

15 J. N. Hall, J. W. Jones and A. K. Sachdev in D. I. Higa (compiler), 14th Annu. Discontinuously Reinforced MMC Working Group Meet., 1992, MMCIAC, Santa Barbara, CA, pp. 6-1. 
16 I. S. Raju and J. C. Newman, in J. H. Underwood, R. Chait, C. W. Smith, D. P. Wilhem, W. A. Andrews and J. C. Newman (eds.), ASTM Spec. Tech. Publ. 505, 1986, p. 789 (ASTM, Philadelphia, PA).

17 J. N. Hall, J. W. Jones and A. K. Sachdev, in J.-P. Bailon and J. I. Dickson (eds.), Fatigue '93, 1993, Engineering Materials Advisory Services, Cradely Heath, p. 1129.

18 W. A. Logsdon and P. K. Liaw, Eng. Fract. Mech., 24 (1986) 737.

19 R. J. Arsenault, L. Wang and C. R. Feng, Acta Metall. Mater., 39 (1991) 47.

20 R. M. Aikin, Jr and L. Christodoulou, Scr. Metall., 25 (1991) 9.

21 W. S. Miller and F. J. Humphreys, Scr. Metall. Mater, 25 (1991) 33.

22 V. C. Nardone and K. M. Prewo, Scr. Metall, 20 (1986) 43.

23 V. M. Karbhari and D. J. Wilkins, Scr. Metall. Mater., 25 (1991) 707.

24 M. Taya, K. E. Lulay and D. J. Lloyd, Acta Metall. Mater., 39 (1991) 73.

25 A. G. Evans, J. W. Hutchinson and R. M. McMeeking, Scr. Metall. Mater., 25 (1991) 3.

26 V. C. Nardone, Scr. Metall., 21 (1987) 1313.

27 R. J. Arsenault, Mater. Sci. Eng., 64 (1984) 171.

28 Aluminium Standards and Data, Aluminium Association Inc., Washington, DC, 1988.

29 T. Christman and S. Suresh, Acta Metall., 36 (1988) 1691.

30 J. Llorca, Acta Metall. Mater., 42 (1994) 151.

31 D. B. Zahl and R. M. McMeeking, Acta Metall. Mater, 39 (1991) 1117

32 Y. L. Shen, M. Finot, A. Needleman and S. Suresh, Acta Metall. Mater.,42(1994) 77.

33 G. Bao, Acta Metall. Mater., 40 (1992) 2547.

34 Y. Wu and E. J. Lavernia, Scr. Metall. Mater., 27 (1992) 173.

35 S. J. Harris, Mater. Sci. Technol., 4 (1988) 231.
36 C. R. Crowe and D. F. Hasson, in R. C. Gifkins (ed.), Strength of Metals and Alloys, ICSMA 6, Pergamon, Oxford, Vol. 2, 1982, p. 859.

37 D. F. Hasson, C. R. Crowe, J. S. Ahearn and D. C. Cook, in J. Early, R. Shives and J. Smith (eds.), Failure Mechanisms in High Performance Materials, Cambridge University Press, Cambridge, 1984, p. 147.

38 S. J. Harris and T. E. Wilks, I. Mech. Eng. C, 37 (1986) 19.

39 J. Llorca, A. Bloyce and T. M. Yue, Mater. Sci. Eng. A, 135 (1991) 247.

40 S. W. Holcomb, Master's Thesis, UCLA, 1991.

41 N. J. Hurd, Mater. Sci. Technol., 4 (1988) 513.

42 D. R. Williams and M. E. Fine, Proc. 5th Int. Conf. on Composite Materials (ICCM5), 1985, TMS, Warrendale, PA, 1985 , p. 639.

43 D. L. Davidson, Eng. Fract. Mech., 33 (1989) 965.

44 A. G. Evans, Metall. Trans. A, 14 (1983) 1349.

45 T. Lin, A. G. Evans and R. O. Ritchie, Metall. Trans. A, 18 (1987) 641

46 K. Wallin, T. Saario and K. Torronen, Int. J. Fract., 32 (1987) 201.

47 J. Llorca, A. Needleman and S. Suresh, Acta Metall. Mater., 39 (1991) 2317.

48 M. Manoharan and S. V. Kamat, Scr. Metall. Mater., 25 (1991) 2121.

49 M. Taya and R. J. Arsenault, Metal Matrix Composites Thermomechanical Behavior, Pergamon, New York, 1989, p. 32.

50 J. W. Hutchinson, J. Mech. Phys. Solids, 16 (1968) 13.

51 J. R. Rice and G. R. Rosengren, J. Mech. Phys. Solids., 16 (1968) 1.

52 S. Suresh, Y. Sugimura and E. K. Tschegg, Scr. Metall. Mater., 27 (1992) 1189.

53 H. J. Kim, T. Kobayashi, H. S. Yoon and E. P. Yoon, Mater. Sci. Eng. A, 154 (1992) 35. 